\title{
Cardiac function of children with Duchenne muscular dystrophy
}

\author{
AbdelrheemAbdraboSadek ${ }^{1}$, Shaimaa M. Mahmoud ${ }^{2}$,Walaa Ibrahim A. ${ }^{3}$ \\ (1) Assistant professor of neuropediatrics, Sohag faculty of medicine. \\ (2) Lecturer of pediatrics, Sohag faculty of medicine. \\ (3) Resident of pediatrics, Sohag faculty of medicine.
}

\begin{abstract}
Background:Duchenne muscular dystrophy (DMD) is the most common childhood form of muscular dystrophy. Clinical guidelines recommend that evaluations for cardiomyopathy, arrhythmia, and heart failure be performed upon diagnosisThe incidence of cardiomyopathy in DMD increases with age Early detection of muscular dystrophy associated cardiomyopathy is

important, because institution of cardioprotective medical therapies may slow adverse remodeling and attenuate heart failure symptoms in these patients.

Aim: evaluation of cardiac function in children clinically suspected to have Duchenne muscular dystrophy.

Methods:28 male children who met criteria for diagnosis of Duchenne muscular dystrophy aged from 3 to 18 years compared to $\mathbf{4 7}$ healthy control children were approached to participate in the study and, after consent, were submitted to full clinical examination, blood samples were collected to determinate CPK (creatinine phosphokinase), Troponin I enzyme, Myoglobin and LDH (lactate dehydrogenase) enzyme level,echocardiography and 12-lead electrocardiogram were done.
\end{abstract}

\section{Results:}

28 Duchenne muscular dystrophy children and $\mathbf{4 7}$ age matched healthy male control children were included in the study. The mean age of study group was 7.29 $\pm \mathbf{3 . 2 4}$ years, and the mean age of the control group was $\mathbf{8 . 0 6} \pm \mathbf{2 . 8 6}$ years ( $p$ value $\mathbf{0} . \mathbf{2 8}$ ). $\mathbf{2 5 \%}$ of cases had Positive family history of DMD. $\mathbf{3 5 . 7 \%}$ of cases had positive consanguinity.all our cases had elevated CPK level (creatine phosphokinase) .The mean CPK level of cases was $\mathbf{2 4 9 5 . 7 9} \pm \mathbf{3 4 5 7 . 0 2}$ While CPK level in controls was normal, ( $\mathrm{p}$ value<0.0001). LDH level was elevated in $\mathbf{1 9}$ cases $\mathbf{6 7 . 8 6 \%}$ of cases. The mean serum LDH level in DMD cases was $1232.07 \pm 6 \mathbf{6 1 7 . 7 2}$. All control children have normal LDH level with mean $163.02 \pm \mathbf{1 0 9 . 6 2}$, ( $\mathrm{P}$ value $\mathbf{0}<\mathbf{0 . 0 0 0 1}$ ). The mean serum myoglobin level of (DMD) patients was higher relative to that of healthy controls (but still within normal limits) $\mathbf{3 9 . 3 9} \pm \mathbf{7 . 2 5}$ versus $33.68 \pm \mathbf{1 2 . 3 8}(\mathrm{ng} / \mathrm{ml})$ respectively with statistically significant difference (P value: 0.01).There was no statistically significant difference between mean serum troponin I level of DMD patients and that of controls $\mathbf{0 ~} \mathbf{. 0 3} \pm \mathbf{0 . 0 5}$ versus $\mathbf{0 . 0 1} \pm \mathbf{0} .02(\mathrm{U} / \mathrm{L})$ respectively (p value: 0.37). Echocardiography of our patients revealed that one patient $(\mathbf{3 . 5 7 \%})$ had mild dilation of the left ventricular cavity which was statistically not significant, (P value: $\mathbf{0 . 3 7}) .7$ cases $(\mathbf{2 5 \%})$ of patients had low Ejection fraction (EF) and fraction shortening (FS) with mean (EF) $\mathbf{5 9 . 8 6} \pm \mathbf{1 0 . 2 0}$. All control children have normal EF with mean 73.30 $\pm \mathbf{5 . 0 8}$ ( $\mathrm{P}$ value : $<\mathbf{0 . 0 0 0 1}$ ). The mean FS was 20.29 $\pm \mathbf{5 . 5 9}$. All control children had normal (FS) with mean \pm SD 36.17 $\pm \mathbf{2 . 5 8}$ (P value : <0.0001). Electrocardiogram showed $\mathbf{2 8 . 5 7 \%}$ of cases had sinus tachycardia with average heart rate (HR) $107 \pm \mathbf{1 2 . 3 2} \mathbf{1 3 6}$. While $\mathbf{6 . 8 8 \%}$ of controls had sinus tachycardia; (P value: 0.0001). Prolonged QTc interval was present in39.29\% 
of cases with a mean of $\mathbf{4 3 1 . 3 9} \pm \mathbf{4 3 . 6 0}$ and that of controls was $\mathbf{4 1 5 . 1 7} \pm \mathbf{2 5 . 2}$ (p value : $<\mathbf{0 . 0 0 0 1}$ ). QTc duration of controls were normal for age. Other parameters of ECG were normal for age; no type of arrhythmia could be detected apart from sinus tachycardia.

Conclusion:ECG manifestations in children with DMD in the form of sinus tachycardia and prolonged QTC interval are an early alarm for developing cardiomyopathy before overt echocardiographic findings appear

Key words:Duchenne muscular dystrophy, echocardiography, electrocardiography, cardiac.

\section{Introduction}

Duchenne muscular dystrophy (DMD) is the most common childhood form of muscular dystrophy. This condition segregates in families with an X-linked pattern of inheritance, though approximately $\mathbf{2 5 \%}$ of cases are due to de novo gene mutations (1).Duchenne muscular dystrophy occurs in about $\mathbf{1}$ out of every 3,600 male infants. Children with DMD typically display skeletal muscle weakness by age 2-6 years(2).Cardiomyopathy is nearly ubiquitous, although the age of onset varies considerably (2-4). Clinical guidelines recommend that evaluations for cardiomyopathy, arrhythmia, and heart failure be performed upon diagnosis, every 2 years thereafter until age $\mathbf{1 0}$ years, and then at least yearly thereafter (3). The incidence of cardiomyopathy in DMD increases with age, affecting $30 \%$ of patients by 14 years of age, $\mathbf{5 0} \%$ of patients by $\mathbf{1 8}$ years of age, and up to $90 \%$ of older patients (5). Early detection of muscular dystrophy associated cardiomyopathy isimportant, because institution of cardioprotective medical therapies may slowadverse remodeling and attenuate heart failure symptoms in these patients.So we conducted this study to evaluate cardiac functions in clinically suspected DMD children by clinical evaluation, cardiac biomarkers echocardiography and electrocardiography (ECG).

\section{Patients and methods}

Study design: A Prospective case control studywas conducted in theNeuropediatric outpatient clinicand pediatric cardiology clinic at Sohag University Hospital. The
Hospital is a tertiary health institution, located in the south zone of Egypt. 28 male children who met criteria for diagnosis of Duchenne muscular dystrophy aged from 3 to 18 years compared to $\mathbf{4 7}$ healthy control children and had given informed consent were included in the study. The diagnosis of Duchenne muscular dystrophy was made on the basis of the clinical characteristics together with serum creatine kinase (CK) determinations. We excluded from the study patients who did not give consent. Also we excluded Children with other types of neuromuscular disorders e.g. spinal muscle atrophy, neuropathy, other types of myopathy and myasthenia, Children less than $\mathbf{3}$ years and more than $\mathbf{1 8}$ years and Female children with muscular dystrophy were also excluded. The study protocol was approved by the Research Ethics Board of our institution.

\section{Data collection:}

1. For all the patients enrolled in the study checklist that included the needed data was filled by the investigator. The checklist included data of the patients concerning age, sex, duration of weakness, with special attention to family history of neuromuscular disorder and motor development, examination of vital signs, full cardiac and neurologic examination.

2. Blood samples were collected from the patients. They were analyzed for serum CPK (creatinine phosphokinase), Troponin I enzyme level, Myoglobin level and LDH (lactate dehydrogenase) enzyme leveland the results were documented in the checklist. 
3. echocardiography :All patients had 2-D and M-mode echocardiographic examinations which included evaluation of left ventricular systolic function. Assement of ejection fraction (Ef) and fractional shortening (FS) and left ventricular dilatation. Results were analyzedin accordance with the American Society of Echocardiography standards.

4. ECG: 12 leads ECG was performed to all children(Fukuda Denshi CardiMax ECG device model FCP-7101 with a $25 \mathrm{~mm} / \mathrm{s}$ paper speed, gain $\mathbf{1 0} \mathrm{mm} / \mathrm{mV}$ ). The electrocardiograms were reviewed through the creation of descriptive reports and determination of the following variables: heart rate, QRS duration and QRS amplitude. The QT interval was measured from the onset of the QRS complex to the end of the $T$ wave, defined by the return of the terminal Twave to the isoelectric TP baseline. When $U$ waves were present, the end of the $\mathrm{T}$ wave was taken as the nadir between the $\mathrm{T}$ and $\mathrm{U}$ waves. Then QT interval was corrected for heart rate using Bazett's formula $(\mathbf{6}-\mathbf{8})$. Interpretation of every ECG paper was done using specific centile tables for normal values of ECG waves and intervals according to age (9). ECG was examined for any abnormal rhythm (ectopics, supraventricular or ventricular tachycardia) .

\section{Statistical analysis}

Data was analyzed using STATA intercooled version 12.1. Quantitative data was represented as mean, standard deviation, median and range. Data was analyzed using student t-test to compare means of two groups. When the data was not normally distributed Mann-Whitney test was used. Qualitative data was presented as number and percentage and compared using either Chi square test or fisher exact test. Graphs were produced by using Excel or STATA program. $\mathrm{P}$ value was considered significant if it was less than $\mathbf{0 . 0 5}$.

\section{Results}

Our study involved $\mathbf{2 8}$ clinically suspected Duchenne muscular dystrophy children and $\mathbf{4 7}$ age matched healthy male children as controls. The mean age of study group was $\mathbf{7 . 2 9} \pm \mathbf{3 . 2 4}$ years, range from 3-14 years and the mean age of the control group was $\mathbf{8 . 0 6} \pm \mathbf{2}$. 86 years, with age range from 3 to 14 years ( $p$ value $\mathbf{0 . 2 8}$ ). $25 \%$ of cases had Positive family history of DMD.

$\mathbf{3 5 . 7 \%}$ of cases had positive consanguinity.

All reported cases had felt the onset of symptoms and muscle weakness between 4-6 years of age. 25 patients had abnormal gait, three were already wheelchair- bound. Heart rate was above normal ranges in $\mathbf{7}$ cases $(\mathbf{2 5 \%})$.

In our study we found that all the cases had elevated CPK level (creatine phosphokinase) .The mean CPK level of cases was $\mathbf{2 4 9 5 . 7 9} \pm \mathbf{3 4 5 7 . 0 2}$ and range from 425 to 11452 . While CPK level in controls was normal, (p value<0.0001). LDH level was elevated in 19 cases $67.86 \%$ of cases. The mean serum LDH level was $\mathbf{1 2 3 2 . 0 7} \pm \mathbf{6 1 7 . 7 2}$. All control children have normal LDH level with mean 163.02 $\pm \mathbf{1 0 9 . 6 2}$, (P value : $<\mathbf{0 . 0 0 0 1}$ ). The mean serum myoglobin level of (DMD) patients was higher relative to that of healthy controls (but still within normal limits) 39.39 $\pm \mathbf{7 . 2 5}$ versus $\mathbf{3 3 . 6 8} \pm \mathbf{1 2 . 3 8}(\mathrm{ng} / \mathrm{ml})$ respectively with statistically significant difference $(\mathrm{P}$ value: 0.01). There was no statistically significant difference between mean serum troponin I level of DMD patients and that of controls $\mathbf{0 . 0 3} \pm \mathbf{0 . 0 5}$ versus $\mathbf{0 . 0 1} \pm \mathbf{0 . 0 2}$ (U/L) respectively ( $\mathrm{p}$ value: $\mathbf{0 . 3 7}$ ) table [1]. 
Table 1: serum biomarkers in studied populations:

\begin{tabular}{|c|c|c|c|}
\hline parameter & $\begin{array}{l}\text { Cases } \\
\mathrm{N}=28\end{array}$ & $\begin{array}{l}\text { Controls } \\
\mathrm{N}=47\end{array}$ & P value \\
\hline $\begin{array}{l}\text { CPK level } \\
\text { Mean } \pm \text { SD } \\
\text { Median (range) }\end{array}$ & $\begin{array}{l}2495.79 \pm 3457.02 \\
557(245-11452)\end{array}$ & $\begin{array}{l}36.19 \pm 10.11 \\
35(21-60)\end{array}$ & $<0.0001$ \\
\hline $\begin{array}{l}\text { CPK group } \\
\text { High } \\
\text { Normal }\end{array}$ & $\begin{array}{l}28(100 \%) \\
0\end{array}$ & $\begin{array}{l}0 \\
47(100 \%)\end{array}$ & $<0.0001$ \\
\hline $\begin{array}{l}\text { Troponin I } \\
\text { Mean } \pm \text { SD } \\
\text { Median (range) }\end{array}$ & $\begin{array}{l}0.03 \pm 0.05 \\
0.007(0.0001-0.15)\end{array}$ & $\begin{array}{l}0.01 \pm 0.02 \\
0.002(0.0001-0.10)\end{array}$ & 0.37 \\
\hline $\begin{array}{l}\text { Troponin I group } \\
\text { Normal }\end{array}$ & $28(100 \%)$ & $47(100 \%)$ & 1.00 \\
\hline $\begin{array}{l}\text { Myoglobin level } \\
\text { Mean } \pm \text { SD } \\
\text { Median (range) }\end{array}$ & $\begin{array}{l}39.39 \pm 7.25 \\
38.5(30-53)\end{array}$ & $\begin{array}{l}33.68 \pm 12.38 \\
33(16-4764)\end{array}$ & 0.01 \\
\hline $\begin{array}{l}\text { Myoglobin group } \\
\text { Normal }\end{array}$ & $28(100 \%)$ & $47(100 \%)$ & 1.00 \\
\hline $\begin{array}{l}\text { LDH level } \\
\text { Mean } \pm \text { SD } \\
\text { Median (range) }\end{array}$ & $\begin{array}{l}1232.07 \pm 617.72 \\
1503(233-2425)\end{array}$ & $\begin{array}{l}163.02 \pm 109.62 \\
137(45-762)\end{array}$ & $<0.0001$ \\
\hline $\begin{array}{l}\text { LDH group } \\
\text { No } \\
\text { Yes }\end{array}$ & $\begin{array}{l}19(67.86 \%) \\
9(32.14 \%)\end{array}$ & $\begin{array}{l}0 \\
47(100 \%)\end{array}$ & $<0.0001$ \\
\hline
\end{tabular}

Echocardiography of our patients revealed that one patient (3.57\%) had mild dilation of the left ventricular cavity which was statistically not significant, (P value: $\mathbf{0 . 3 7 ) . 7}$ cases(25\%) of patients had low Ejection fraction (EF) and fraction shortening (FS) withmean (EF) $\mathbf{5 9 . 8 6} \pm \mathbf{1 0 . 2 0}$ and range from 45 to 80. All control children have normal EF with mean $73.30 \pm 5.08$ and range from 75 to80, (P value : <0.0001). The mean FS was $\mathbf{2 0 . 2 9} \pm 5.59$ with range from 22 to 41 . All control children had normal (FS) with mean \pm SD 36.17 \pm 2.58 and range from 28 to 40, (P value $:<0.0001)$ table $[2]$. 
Table (2): Echocardiographic parameters in studied populations:

\begin{tabular}{|c|c|c|c|}
\hline parameter & Cases & Controls & P value \\
\hline $\begin{array}{l}\text { EF } \\
\text { Mean } \pm \text { SD } \\
\text { Median (range) }\end{array}$ & $\begin{array}{l}59.86 \pm 10.20 \\
59(45-80)\end{array}$ & $\begin{array}{l}73.30 \pm 5.08 \\
75(57-80)\end{array}$ & $<0.0001$ \\
\hline $\begin{array}{l}\text { EF group } \\
\text { Low } \\
\text { Normal } \\
\end{array}$ & $\begin{array}{l}7(25.00 \%) \\
21(75.00 \%)\end{array}$ & $\begin{array}{l}0 \\
47(100 \%)\end{array}$ & 0.0001 \\
\hline $\begin{array}{l}\text { FS } \\
\text { Mean } \pm \text { SD } \\
\text { Median (range) }\end{array}$ & $\begin{array}{l}20.29 \pm 5.59 \\
30(22-41)\end{array}$ & $\begin{array}{l}36.17 \pm 2.58 \\
37(28-40)\end{array}$ & $<0.0001$ \\
\hline $\begin{array}{l}\text { FS group } \\
\text { Low } \\
\text { normal }\end{array}$ & $\begin{array}{l}7(25.00 \%) \\
21(75.00 \%)\end{array}$ & $\begin{array}{l}0 \\
47(100 \%)\end{array}$ & 0.001 \\
\hline $\begin{array}{l}\text { Left ventricular } \\
\text { dilation }\end{array}$ & Cases & Controls & $P$ value \\
\hline $\begin{array}{l}\text { Yes } \\
\text { No }\end{array}$ & \begin{tabular}{|l|}
$1(3.57 \%)$ \\
$27(96.43 \%)$ \\
\end{tabular} & $\begin{array}{l}0 \\
47(100 \%)\end{array}$ & 0.37 \\
\hline
\end{tabular}

Electrocardiogram showed $\mathbf{2 8 . 5 7 \%}$ of cases had sinus tachycardia with average heart rate $\mathbf{1 0 7}$ $\pm \mathbf{1 2 . 3 2}$. While $\mathbf{6 . 8 8 \%}$ of controls had sinus tachycardia with average heart rate of control group

96.02 $\pm \mathbf{1 2 . 3 5}$ (P value: 0.0001). ProlongedQTc interval was present in39.29\% of cases, the meanQTc interval was $\mathbf{4 3 1 . 3 9} \pm \mathbf{4 3 . 6 0}$ and that of controls was $\mathbf{4 1 5 . 1 7} \pm \mathbf{2 5 . 2 4}$ (p value $\mathbf{:}<\mathbf{0 . 0 0 0 1}$ ) table [3]. Correlating QTc interval to ejection fraction revealed that no significant correlation present $(\mathrm{P}$ value $=\mathbf{0 . 8})$.

All QTc duration values of controls were normal for age. Other parameters of ECG including (pwave amplitude and duration, PR interval QRS duration, axis and voltage and QT interval) were normal for age; no type of arrhythmia could be detected apart from sinus tachycardia figure [1]. 


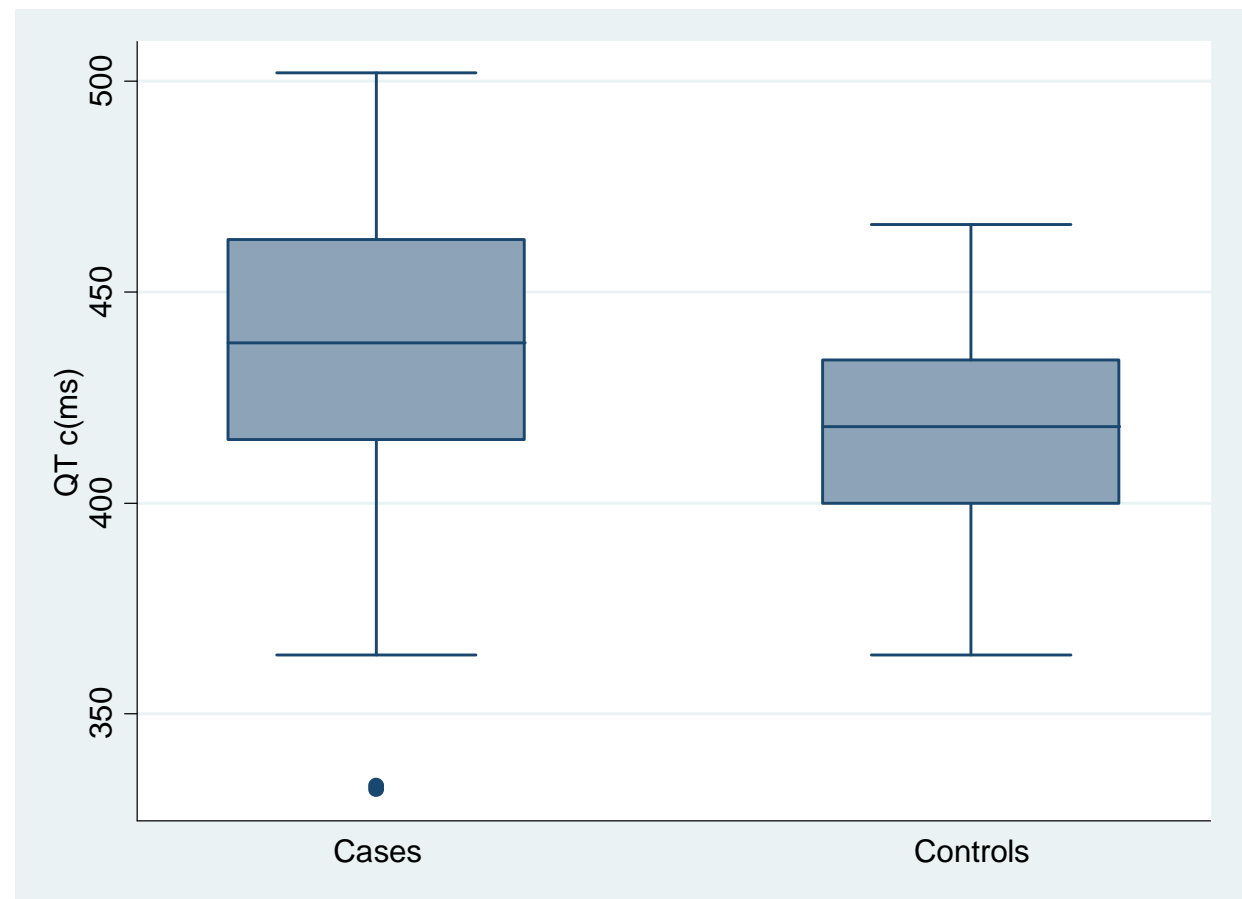

Figure (1): Comparison between cases and controls as regards $\mathrm{QT}_{\mathrm{c}}$ duration (ms).

\section{Discussion}

Duchenne muscular dystrophy is an inherited X-linked disease associated with absence of dystrophin(10).it is characterized by progressive muscle weakness and inescapable cardiac involvement (11). Children with DMD typically display skeletal muscle weakness by age 2-6 years (2).Cardiomyopathy is nearly ubiquitous; although the age of onset varies considerably $((\mathbf{3}, \mathbf{4})$. This suggests that factors other than the absence of dystrophin contribute to cardiomyopathy.Early detection of muscular dystrophy associated cardiomyopathy is important, because institution of cardioprotective medical therapies may slow adverse remodeling and attenuate heart failure symptoms in these patients (12-15). So we conducted our study to detect early subclinical cardiomyopathy as it became now a major cause of morbidity and mortality with increased life expectancy of DMD patients.
The age of our patients range from 3-14 years. 25\% of cases had Positive family history of DMD. $\mathbf{3 5 . 7 \%}$ of cases had positive consanguinity. In Gesmar et al., study the age ranged from 6 to $\mathbf{1 4}$ years and $\mathbf{4 5 \%}$ of his cases had a positive family history of DMD (16).creatine kinase, troponin I , myoglobin, , and lactate dehydrogenase are serum markers of muscle injury (17-19). All our cases had high CPK level, as it is a mainstay in diagnosis of DMD , However results of myoglobin were relatively near to the results of Hathout et al.(20).cardiomyopathy that develops in DMD is characterized by normal or thinned left ventricular (LV) wall thickness and progressive decline in ejection fraction or fractional shortening. Variable degrees of LV dilation occur. Abnormal LV relaxation has also been identified as an early manifestation in DMD (21). 
Our echocardiographic findings agrees with Jefferies et al., who documented that Cardiac disease in DMD population usually consists of dilated cardiomyopathy, which causes progressive decline in the ejection fraction and fractional shortening, and generally evolves to heart failure, even with concomitant arrhythmia (13). 34\% of DMD cases in the study of Philip et al., developed cardiomyopathy with follow up (22)., and $\mathbf{3 0 \%}$ of DMD cases in the study of Tamara et al developed cardiomyopathy

(23). Spurney et al., documented that The age of onset varies considerably, but abnormalities in systolic function are present in more than $80 \%$ of boys older than 18 years of age (24).Our electrocardiographic findings agree with that of Tamara et al., who hypothesized that an elevated heart rate would herald cardiomyopathy onset(23). In our study QTc prolongation was present regardless presence or absence of echocardiographic findings of cardiomyopathy, this agrees with findings of Philip et al.,who postulated that in their study, ECG changes are similar in patients with DMD regardless of presence of dilated cardiomyopathy (24).Martin et al., documented that a significant number of patients $(\mathbf{2 4 \%}$ to $\mathbf{3 2 \%})$ with dilated or hypertrophic cardiomyopathy may have a long QTc interval on the surface ECG, and ventricular hypertrophy/dilation may be additional rare causes of acquired prolongation of the QT interval.A lengthening of the QT interval predisposes to torsade de pointes ventricular tachycardia, which can degenerate into ventricular fibrillation (25).

\section{Conclusion:}

ECG manifestations in children with DMD in the form of sinustachycardia and prolonged QTCinterval are anearly alarm for developing cardiomyopathy before overt echocardiographic findings appear.

\section{Refrences}

1. Tuffery-Giraud S, Beroud C, Leturcq F, et al.; Genotype-phenotype analysis in $\mathbf{2 , 4 0 5}$ patients with a dystrophinopathy using the UMD-DMD database: a model of nationwide knowledgebase. Hum Mutat; 30 (6): 934-45, 2009.

2. Boland BJ, Silbert PL, Groover RV, et al.: Skeletal, cardiac, and smooth muscle failure in Duchenne muscular dystrophy. PediatrNeurol ;14 (1):7-12, 1996 .

3. Bushby K, Muntoni F, Bourke JP.: 107th ENMC International Workshop: The Management of Cardiac Involvement in Muscular Dystrophy and Myotonic Dystrophy, 7th-9th June 2002, Naarden, the Netherlands. NeuromusculDisord; 13:166-172, 2003.

4. Wagner KR, Lechtzin N, Judge DP.: Current treatment of adult Duchenne muscular dystrophy. BiochimBiophysActa; 1772 (2): 229-37, 2007.

5. Kwon SW, Kang S, Kim J, et al.: Outcomes of cardiac involvement in patients with late-stage Duchenne muscular dystrophy under management in the pulmonary rehabilitation center of a tertiary referral hospital. Cardiology. ; 121:186-93, 2012.

6. Hampton JR. The ECG Made Easy. 7th edition. London: Churchill Livingstone 2008.

7. Morris STW,Galiatsou E, Stewart GA,et al: QT dispersal before and after dialysis. $J$ AmSocNephrol10:160-163, 1999.

8. Galliatsou E, Morris S, Jardine AG, et al: Cardiovascular abnormalities in renal transplant patients: Differential effects of cyclosporine and azathioprine. $J$ Nephrol13:185-192, 2000.

9. R. Rijnbeek, M. Witsenburg, E. Schrama, J. Hess and J. A. Kors, Normal limits for the paediatricECG ,Eur Heart J, April 2001.

10. Emery AEH. :Duchenne muscular dystrophy or Meryon's disease. In:The Muscular Dystrophies. 2nd edition. Oxford: Oxford University Press, 55-71, 1993.

11. Melacini P, Vianello A, Villanova $C$, et al.; Cardiac and respiratory involvement in 
advanced stage Duchenne muscular dystrophy. 19. Brancaccio, P., Lippi, G., and Maffulli, N., : Neuromuscular Disord ;6:367-376, 1996. Biochemical markers of muscular damage.

12. Duboc D, Meune C, Pierre B, Wahbi K, Eymard B, Toutain A, et al.: Perindopril 20. preventive treatment on mortality in Duchenne muscular dystrophy: 10 years' follow-up. Am Heart J 154:596-602, 2007.

13. Jefferies JL, Eidem BW, Belmont JW, Craigen WJ, Ware SM, Fernbach SD, et al.: Genetic predictors and remodeling of dilated cardiomyopathy in muscular dystrophy. Circulation ;112 :2799-2804, 2005.

14. Kajimoto $H$, Ishigaki $K$, Okumura $K$, Tomimatsu H, Nakazawa M, Saito K, et al.: Beta-blocker therapy for cardiac dysfunction in patients with muscular dystrophy. Circ J ;70:991-994, 2006.

15. Ramaciotti C, Heistein LC, Coursey M, Lemler MS, Eapen RS, Iannaccone ST, Scott WA.: Left ventricular function and response to enalapril in patients with Duchenne muscular dystrophy during the second decade of life.Am J Cardiol. ; 98:825-827, 2006.

ClinChem Lab Med;48(6): 757-767, 2010.

20. Hathout, Y., Brody, E., Clemens, P. R., Cripe, L., DeLisle, R. K., Furlong, P.,Gold L.: Largescale serum protein biomarker discovery in Duchenne muscular dystrophy.Proceedings of the National Academy of Sciences of the United States of America, 112(23), 7153-7158, 2015.

21. Markham LW, Michelfelder EC, Border $1 \mathrm{WL}$, Khoury PR, SpicerRL, Wong BL, et al. Abnormalities of diastolic function precede dilated cardiomyopathy associated with Duchenne muscular dystrophy. J Am SocEchocardiogr ;19:865-871, 2006.

22. Philip T., Thrush, Hugh D. Allen, Laurence Viollet,Jerry R. Mendell :.Re-examination of the Electrocardiogram in Boys With Duchenne Muscular Dystrophy and Correlation With Its Dilated Cardiomyopathy.The American Journal of Cardiology Volume 103, Issue 2, Pages 262-265, 2009.

16. Gesmar Volga Haddad Herd, Roberta Duarte 23. Tamara O. Thomas ,Thomas M, Morgan Bezerra Pinto Guilherme de Almeida Costa Ana FlaviaMalheirosTorbey, VivianneGalante Ramos., MarcioMoacyrVasconcelos., Clinical and Molecular Study on Duchenne Muscular $\begin{array}{lcc}\text { Dystrophy. internacional } & \text { Journal of } 24 . \\ \text { Cardiovascular } & \text { Sciences. } & \mathbf{; 2 8 ( 3 ) : 1 7 3 - 1 8 0 ,}\end{array}$ 2015.

17. Ohlendieck, K. Proteomic identification of biomarkers of skeletal muscle disorders. Biomark Med; 7(1): 169-186, 2013.

18. Carp, S. J., Barr, A. E., and Barbe, M. F., : Serum biomarkers assignals for risk and severity of work-related musculoskeletal injury. Biomark Med.; 2(1): 67-79, 2008. William, B. Burnette ,Larry W.; Markham. Correlation of Heart Rate and Cardiac Dysfunction in Duchenne Muscular Dystrophy .pediatrCardiol ;33:1175-1179, 2012 .

24. Spurney, Christopher F. :Cardiomyopathy of Duchenne muscular dystrophy: current understanding and future directions." Muscle \&nerve ;44.1: 8-19, 2011.

25. Martin AB, Garson A Jr, Perry JC. Prolonged QT interval in hypertrophic and dilated cardiomyopathy in children. Am Heart J. 1994 Jan;127(1):64-70. 